\title{
Mulheres e gênese do capitalismo: de Foucault a Federici
}

\author{
Women and genesis of Capitalism: \\ from Foucault to Federici
}

\author{
Silvana de Souza Ramos \\ Professora Livre-docente do Departamento \\ de Filosofia da USP
}

Resumo: O livro de Federici, O Calibã e a Bruxa, se articula a partir de três eixos: a crítica aos limites das análises de Marx no intuito de explicar a gênese do capitalismo uma vez que negligenciam o papel das mulheres neste processo; a crítica à genealogia foucaultiana da Modernidade, uma vez que, ao dar centralidade ao caráter produtivo do poder, deixa de lado a análise da repressão estatal como elemento decisivo para o adestramento do comportamento das mulheres; por fim, a pesquisa em torno do fenômeno histórico de caça às bruxas, ocorrido na Europa entre os séculos XVI e XVII, ou seja, durante a ascensão do capitalismo enquanto modo de produção preponderante no Ocidente. Meu objetivo é realizar uma apresentação destes três eixos, dando ênfase ao diálogo de Federeci com Foucault. Trata-se, por um lado, de apresentar a posição da autora com relação à genealogia da mulher no interior da ordem capitalista, a qual se constrói principalmente em torno de uma discussão com o livro História da Sexualidade I, e, por outro, de mostrar que as questões levantadas por ela ganham maior envergadura se tomamos Vigiar e Punir enquanto obra responsável pelo diálogo entre os dois autores. 
Palavras-chave: Mulher; Capitalismo; Patriarcado; Corpo; Michel Foucault; Silvia Federici

Abstract: Silvia Federici's book, Caliban and the Witch, is based on three fundamental axes: the critique of the limits of the Marxian analyzes in order to explain the genesis of Capitalism since they neglect the role of women in this process; the critique of the Foucauldian genealogy of Modernity, since, by giving centrality to the productive character of power, it sets aside the analysis of state repression as a decisive element for the training of women's behaviors at the beginning of the capitalist order; finally, the research on the historical phenomenon of witch hunting, which occurred in Europe between the 16th and 17th centuries, that is, during the rise of capitalism as a predominant mode of production in the West. My aim is to present these three axes, but giving emphasis to the Federeci's dialogue with Foucault. On the one hand, I present the author's position regarding the genealogy of women within the capitalist order, which is mainly built around a discussion with the book History of Sexuality I. On the other hand, I show that the questions raised by Federici gain greater scope if one takes Discipline and Punish as the work responsible for the dialogue between the two authors.

Keywords: Woman; Capitalism; Patriarchate; Body; Michel Foucault; Silvia Federici

\section{Introdução}

A pesquisa de Silvia Federici acerca das raízes da moderna Aexploração social e econômica das mulheres, trabalho iniciado nos anos 1970 e que dá corpo ao estudo da gênese do capitalismo apresentada em O Calibã e a Bruxa - Mulheres, corpo e acumulação primitiva, explicitam uma série de lacunas no que diz respeito à análise da profunda articulação entre patriarcado e capitalismo e a necessidade de novos estudos que permitam preenchê-las. Não deixa de ser espantoso o fato de que a caça às bruxas, fenômeno que dizimou centenas de milhares de mulheres na Europa e nas colônias americanas ao longo dos séculos XVI e XVII, tenha despertado tão pouco a curiosidade dos historiadores interessados na gênese da Modernidade e do 
capitalismo. O fato de o Estado moderno ter, na aurora do capitalismo, empreendido uma voraz perseguição às mulheres e uma punição atroz de hábitos e comportamentos antes aceitáveis - tais como a profissão de parteira, as atividades coletivas de trabalho e de celebração, a cura através de poções e de ervas medicinais, as práticas contraceptivas, entre outras - haveria de carregar algum laço estrutural com a formação do novo modo de produção então nascente. Afinal, há aí elementos suficientes para perceber que a bruxa era, não apenas um ser místico, mas, principalmente, a encarnação de sujeitos femininos que o capitalismo precisava destruir para triunfar: a herege, a curandeira, a esposa desobediente, a que ousa viver só, a obeha. ${ }^{69}$ Assim, ao invés de considera-la como um fenômeno lateral e sem relevância histórica, seria necessário empreender um estudo detalhado da caça às bruxas de modo a desvendar um aspecto decisivo da formação da classe proletária. Este estudo explicitaria a especificidade da moderna exploração das mulheres no capitalismo de modo a dar conta de sua necessária domesticação e subordinação aos homens neste novo contexto histórico, subordinação esta que incidiria sobre o corpo feminino e se estruturaria no interior daquilo que se convencionou chamar de patriarcado.

Não se trata, porém, de uma tarefa simples, uma vez que a defesa da hipótese de que haja uma articulação profunda entre patriarcado e capitalismo exige o enfrentamento, por um lado, da ortodoxia marxista, responsável por explicar a opressão de gênero como um resíduo de relações feudais, e, portanto, exterior à gênese do novo modo de produção. Nesse sentido, autoras como Dalla Costa e James, às quais Federici endereça o devido crédito em seu referido livro, mostraram que a exploração das mulheres havia cumprido uma função central

\footnotetext{
69 Cabe salientar que o caráter mágico do saber popular precisava ser combatido por ser avesso à disciplina capitalista do trabalho, uma vez que propiciava a esses sujeitos uma justificável relação não administrada (e imprevisível, portanto) com seus corpos e com a natureza: "A incompatibilidade da magia com a disciplina do trabalho capitalista e com a exigência de controle social é uma das razões pelas quais o Estado lançou uma campanha de terror contra a magia - um terror aplaudido sem reservas por muitos dos que hoje são considerados fundadores do racionalismo científico: Jean Bodin, Mersenne [...], Newton, [...] Hobbes" (Federici, 2017, p. 261).
} 
no processo de acumulação primitiva do capital, pois elas foram produtoras e reprodutoras da mercadoria mais importante nesse contexto: a força de trabalho. Não haveria instauração, tampouco continuidade do capitalismo, se não houvesse força de trabalho disponível, numerosa e adestrada, e, para que essa condição se instalasse, a exploração do corpo e o controle das mulheres foram decisivos, especialmente no que diz respeito ao trabalho reprodutivo. Além disso, para explicar o nascimento e o desenvolvimento do novo modo de produção, era necessário discutir o papel do trabalho doméstico no interior do circuito de exploração capitalista. Segundo essas autoras, o trabalho doméstico não remunerado foi, e ainda é, um pilar necessário para a organização da exploração dos trabalhadores assalariados. Isso significa que a restrição do campo de existência plena das mulheres ao escopo privado do lar e a consequente subordinação destas, tanto econômica quanto política, aos homens, o que Federici entende por patriarcado, não configura um traço acessório do capitalismo. Pelo contrário, dando continuidade aos estudos de Dalla Costa e James, a autora defende que o patriarcado não é uma estrutura atemporal ou trans-histórica, mas sim algo cujo conteúdo histórico específico é possível desvendar. Essa tarefa abre caminho para uma interpretação feminista da história do capitalismo e da luta de classes, algo que vai além do mero estudo da história das mulheres e de seu terrível silenciamento ao longo dos tempos. Afinal, trata-se de mostrar que a negligência com relação ao estudo da moderna exploração das mulheres impede que seja feita uma verdadeira gênese do capitalismo como um todo.

Por outro lado, o desvendamento da articulação entre patriarcado e capitalismo exige que seja revisitada a tópica relativa ao adestramento dos corpos vivos com vistas à produção e à reprodução administrada. Nesse sentido, é espantoso que Foucault, autor atento à mudança nas formas de punição na passagem à Modernidade, tenha sido indiferente à grandiosidade do espetáculo público de queima das bruxas. A especificidade do suplício das mulheres não foi objeto de estudo do filósofo francês, algo que sem dúvida poderia colocar em xeque uma série de conclusões acerca da genealogia do poder defen- 
didas pelo autor de História da Sexualidade I - A Vontade de Saber e de Vigiar e Punir - Nascimento da prisão. Decerto, ao tomarmos a caça às bruxas como um fenômeno decisivo para a compreensão da Modernidade, percebemos que a domesticação do corpo e do comportamento das mulheres - a gênese moderna do indivíduo mulher - está amarrada a um processo vigoroso de repressão estatal. Desse modo, é preciso compreender que a soberania teve, e ainda tem, um papel importante no controle e na disciplina dos hábitos das mulheres. Não foram apenas os aparelhos disciplinares - o hospital, a escola, a prisão, entre outros - os responsáveis pela domesticação desses indivíduos, mas sim uma brutal repressão empreendida pelo Estado, ação que, em determinado momento, passou a visar um campo de ilegalismos antes desprezados, isto é, certos comportamentos típicos das mulheres no declínio da era clássica, especialmente das pobres e das camponesas. Federici nos ajuda a compreender esse ponto - essa espécie de cruzamento entre poder soberano e disciplinar que vigorou no processo de gênese da mulher moderna - ao defender que o capitalismo foi na verdade uma contrarrevolução que solapou as ações de resistência à exploração feudal, especialmente aquelas realizadas pelos trabalhadores e trabalhadoras dos campos europeus, e que uma das suas estratégias fundamentais foi a de dividir a classe oprimida e explorada por meio da desvalorização social das mulheres em relação aos seus pares masculinos.

Sendo assim, o trabalho de Federici revisita os principais eventos que marcaram a vitoriosa repressão àqueles e àquelas que tentaram resistir a certas práticas de exploração presentes no contexto feudal - a contrarrevolução capitalista. É nesse quadro que a caça às bruxas ganha sentido preciso, de modo a mostrar que a gênese do capitalismo exige dois estudos fundamentais: a análise do processo de acumulação primitiva e o estudo do caráter específico da repressão e do disciplinamento das mulheres em relação aos homens, pois se trata de elementos decisivos para a instauração da moderna sociedade patriarcal. No intuito de esclarecer e de discutir o alcance de algumas das conclusões alcançadas por Federici, devemos analisar cada um desses elementos. 


\section{A acumulação primitiva do capital}

Entender o processo de acumulação primitiva do capital exige revisitar a passagem histórica do modo de produção feudal ao capitalista, assunto que ainda hoje gera muitas discussões e polêmicas. ${ }^{70}$ Há uma série de eventos históricos, tais como a expropriação por parte do Estado das terras comunais em várias regiões da Europa, além dos cercamentos que aconteceram na Inglaterra e de outros eventos do mesmo tipo, os quais dão conta de práticas predatórias, abusivas e violentas, promovidas pela burguesia e ancoradas pela ação do Estado, presentes nas origens históricas do capitalismo. Ora, essas práticas dizem respeito a um processo complexo que envolve, de um lado, a crescente concentração da propriedade privada nas mãos de poucos (por isso, a necessidade de destruição das propriedades comunais, existentes no mundo feudal) e, de outro, a formação da classe proletária, a qual deveria dispor apenas de sua força de trabalho, algo a ser oferecido livremente à venda no mercado. Sendo assim, o estudo desse violento processo de acumulação primitiva é decisivo para o desvendamento da gênese do capital porque traz à luz o nascimento de novas relações sociais no interior desse modo de produção em formação, as quais dependem, é evidente, de uma base material precisa. Nas palavras de Marx:

A natureza não produz possuidores de dinheiro e de mercadorias, de um lado, e simples possuidores de suas próprias forças de trabalho, de outro. Essa não é uma relação histórico-natural [naturgeschichtliches], tampouco uma relação social comum a todos os períodos históricos, mas é claramente o resultado de um desenvolvimento histórico anterior, o produto de muitas revoluções econômicas, da destruição de toda uma série de formas anteriores de produção social (Marx, 2013, p. 244).

Dito de outro modo, a expropriação de bens comuns e o acúmulo de propriedade privada e de dinheiro nas mãos de poucos são processos articulados, os quais configuram uma espécie de pré-história do capitalismo, sem o que este não poderia se instalar ou mesmo se desenvolver.

70 Para uma apresentação mais ampla dessa discussão, cf. Harvey, 2013, pp. 229-300. 
Federici retoma essa discussão marxiana acerca da expropriação violenta de toda uma classe de pessoas de qualquer controle sobre os meios de produção na aurora do capitalismo no intuito de produzir sua própria leitura desse fenômeno. É preciso dizer, no entanto, que a autora tem em vista duas lacunas deixadas por Marx. Em primeiro lugar, ela dá um passo atrás para mostrar, através de inúmeros documentos e estudos históricos, que, por volta do fim do século XIV, "a revolta do campesinato contra os senhores feudais havia se tornado constante, massiva e, frequentemente, armada" (Federici, 2017, p. 54). Sendo assim, o primeiro capítulo de Calibã e a Bruxa descreve um mundo feudal dinâmico, atravessado pela luta de classes, período em que o campesinato avançava na conquista de direitos e na preservação de seu excedente de trabalho:

O objetivo principal dos servos era preservar seu excedente de trabalho e seus produtos, ao mesmo tempo em que ampliavam a esfera de direitos econômicos e jurídicos. Esses dois aspectos da luta servil estavam estritamente ligados, já que muitas obrigações decorriam do estatuto legal dos servos (Federici, 2017, p. 54).

A autora analisa a servidão como relação de classe, o papel que a luta pelo comum - especialmente pela propriedade comum - teve no período, a amplitude das atividades das mulheres, uma vez que elas exerciam diversas profissões reconhecidas socialmente, a força das doutrinas hereges, seja no que diz respeito à crítica à Igreja, seja no que se refere à promoção de atividades sexuais e contraceptivas, divergentes das que acabarão por predominar no capitalismo, e a consequente necessidade de sua posterior criminalização, as lutas urbanas promovidas pela diminuição da população por conta dos episódios de peste - algo que deu poder econômico aos sobreviventes nas cidades europeias. Esse contexto efervescente de criatividade e de luta teve como resposta, segundo Federici, uma aliança entre a aristocracia e a burguesia, a qual deu vazão aos processos de acumulação primitiva do capital por meio da expropriação dos trabalhadores e da dissolução dos laços comunais existentes no mundo feudal. 
Ora, o ponto mais importante analisado por Federici se encontra no fato de que essa aliança de classe, no interior de um determinado processo contrarrevolucionário, teve como resultado não a formação da uma classe proletária uniforme, sem divisão interna; pelo contrário, ao visar as mulheres como foco de resistência a ser combatido - já que elas resistiam à expropriação das terras comunais e à alienação do controle de seus próprios corpos -, a autora mostra que era interessante para essa aliança enfraquecer os trabalhadores estabelecendo uma divisão de gênero no seu interior. Um dos exemplos mais contundentes dessa estratégia foi o fato de que o Estado promoveu estupros coletivos, tornando o corpo feminino um bem comum responsável por substituir socialmente o campo das terras agora privatizadas, espécie de compensação dada aos trabalhadores em função de suas perdas. As consequências dessa violência para a posição social das mulheres foram desastrosas, pois ela depreciou significativamente a figura social da mulher, elemento que preparou um terreno propício para que a perseguição às bruxas se instaurasse praticamente sem qualquer resistência popular.

Mas não só isso. A transição ao capitalismo exigiu uma nova divisão sexual do trabalho. Os saberes antes cultivados e utilizados pelas mulheres no contexto feudal - o conhecimento das ervas medicinais ou o saber acerca do parto e das práticas contraceptivas, por exemplo - foram delas violentamente retirados, no mesmo ritmo em que essas práticas passaram a ser criminalizadas, constituindo, assim, uma zona de ilegalidade circunscrita pelo campo da bruxaria. A ciência moderna, por sua vez, agora promovida pelos homens e pelo Estado, tomou pouco a pouco o lugar das antigas crenças e práticas as quais estavam sob a responsabilidade social das mulheres. Federici defende a tese de que a reprodução, por exemplo, era um campo de domínio feminino, e que esse domínio desapareceu enquanto tal, na passagem histórica ao capitalismo, quando a parteira foi gradativamente substituída pelo médico. O novo modo de produção separou o trabalho produtivo, assalariado, tanto do reprodutivo quanto do improdutivo (o trabalho doméstico), 
ambos não-remunerados. ${ }^{71}$ Desse modo, iniciou-se a estruturação social segundo a qual o capitalismo faz uso do salário para controlar o corpo e o trabalho dos não-assalariados, o que acabou por provocar mais uma vez a desvalorização do papel social das mulheres em relação ao que se via no período anterior. Esse processo de divisão e de crescente hierarquia generificada no interior da classe proletária ajuda a compreender a gênese dos conceitos modernos de masculinidade e de feminilidade e, ademais, explicita por que o patriarcado - em que a mulher, desprovida de sua antiga posição social vê-se subordinada ao marido e ao patrão - é inerente à configuração social do capitalismo desde a instalação desse novo modo de produção. ${ }^{72}$

Decerto, Federici concorda com Marx ao sustentar a tese de que a expropriação dos meios de subsistência dos trabalhadores europeus e a escravização dos povos originários da América e da África nas minas e nas plantações do Novo Mundo foram decisivas para a acumulação primitiva. No entanto, ao lado de Calibã (o personagem da revolta anticolonial, presente em A Tempestade, de Shakespeare), a autora dá protagonismo à bruxa, representante da mulher explorada em formação. Se o capitalismo é estruturalmente racista, como já insinuava Marx, é preciso dizer que ele também é estruturalmente misógino. O processo de formação da classe proletária é marcado pela transformação do corpo das mulheres em fábricas de força de

$71 \quad$ Sobre a gênese da figura histórica da dona de casa, e do trabalho doméstico enquanto tal (tendo por referência os estudos de Engels, importantíssimos para essa discussão), cf. o ensaio "A obsolescência das tarefas domésticas se aproxima: uma perspectiva da classe trabalhadora", em Davis, 2016.

72 Por essa razão, Federici utiliza o conceito de mulher em suas análises, embora ela não o essencialize, pelo contrário, trata-se de um produto histórico. Segundo ela: "se na sociedade capitalista a 'feminilidade' foi construída como uma função-trabalho que oculta a produção da força de trabalho sob o disfarce de um destino biológico, a história das mulheres é a história das classes, e a pergunta que devemos fazer é se foi transcendida a divisão sexual do trabalho que produziu esse conceito em particular. Se a resposta for negativa [...], então 'mulher' é uma categoria de análise legítima, e as atividades associadas à reprodução seguem sendo um terreno de luta fundamental para as mulheres [...] e um nexo de união com a história das bruxas" (Federici, 2017, p. 31). 
trabalho disponível para a produção e a reprodução de capital. Esse processo foi alcançado por meio do extermínio das mulheres dissidentes transformadas em bruxas, e pelo terror que essa prática disseminou no corpo social. Nestes termos, a acumulação primitiva foi, de um lado, o acúmulo de trabalhadores exploráveis e de capital. De outro lado, ela se configurou como "uma acumulação de diferenças e de divisões dentro da classe trabalhadora, em que as hierarquias constituídas sobre o gênero, assim como sobre a "raça" e a idade, se tornaram constitutivas da dominação de classe e da formação do proletariado moderno" (Federici, 2017, p. 119).

\section{2. $O$ adestramento dos corpos}

Se o processo de acumulação primitiva é um dos eixos de análise de Federici, não menos importante é o estudo do processo de controle do corpo feminino. A autora insiste em afirmar que Foucault não foi capaz de discutir o caráter específico do disciplinamento das mulheres no registro do capitalismo nascente. É verdade que ela estabelece essa discussão tendo por adversário o autor de História da Sexualidade I - A Vontade de Saber. Nesse sentido, sua apreciação fica restrita à análise do dispositivo de sexualidade, de modo que a não consideração da relação específica entre corpo das mulheres e poder/saber na aurora da Modernidade seria devida à ênfase dada por Foucault ao caráter produtivo do poder nesse período, o que o diferenciaria do poder soberano, predominantemente repressivo. $\mathrm{O}$ adestramento do corpo e o próprio lugar dado à reprodução na Modernidade - o quarto do casal, normatizado pelos saberes nascentes - seriam, assim, explicáveis pela produtividade de um poder que incita a falar sobre sexo e a confessar constantemente todo e qualquer comportamento sexual, o que teria por resultado a normalização desse comportamento e a definição do campo das práticas perversas a serem controladas.

Ora, a pesquisa histórica feita por Federici, a qual envolve inumeráveis documentos, mas também ilustrações que dão notícia da progressiva construção de uma imagem demoníaca da sexualidade feminina - sexualidade que seria perigosa tanto 
para os homens quanto para as crianças, pois envolveria práticas de sedução, de aborto e de infanticídio - contraria a ideia de que a repressão às mulheres seria apenas uma hipótese, sem lastro nas práticas preponderantes na Modernidade. Pelo contrário, esses documentos mostram que a sexualidade feminina foi demonizada e, por consequência, reprimida por meio de uma ampla ação estatal de perseguição política, apoiada pela Igreja e empreendida contra as mulheres, perseguição esta que culminava com a terrível morte na fogueira. Se a confissão teve aí algum papel, este se desenrolou sob intensa tortura, em consonância não com o que Foucault descreve como dispositivo de sexualidade, mas sim de acordo com o que ele apresenta como sendo o dispositivo de soberania, especialmente tal como este aparece na abertura de Vigiar e Punir. Eis uma discussão que Federici não leva adiante, pois ela tem em vista apenas o horizonte de História da Sexualidade I, e não a discussão sobre o poder disciplinar, presente no livro anterior. Nas palavras de Federici:

No caso da caça às bruxas - que Foucault ignora de forma surpreendente em sua História da Sexualidade -, o "discurso interminável sobre o sexo" não foi desencadeado como uma alternativa à repressão, mas a serviço da repressão, da censura, da rejeição. Certamente, podemos dizer que a linguagem da caça às bruxas "produziu" a mulher como uma espécie diferente, um ser sui generis, mais carnal e pervertido por natureza. Também podemos dizer que a produção da "mulher pervertida" foi o primeiro passo para a transformação da vis erotica feminina em vis lovorativa - isto é, um primeiro passo na transformação da sexualidade feminina em trabalho. Mas devemos reconhecer o caráter destrutivo deste processo, que também demonstra os limites de uma "história da sexualidade" genérica, como a proposta por Foucault, que trata a sexualidade a partir da perspectiva de um sujeito indiferenciado, de gênero neutro, e como uma atividade que supostamente tem as mesmas consequências para homens e mulheres (Federici, 2017, p. 345).

A história da sexualidade, narrada do ponto de vista das mulheres, revela um elemento positivo, e nisto Foucault estava certo: a mulher moderna é um efeito de poder, ela é, por consequência, instrumento e alvo do poder. Ela não existia antes da configuração dos dispositivos de poder tal como se cristalizaram na Modernidade. Isso não significa, contudo, que possamos desprezar o caráter negativo - ou, segundo a expres- 
são de Federici, destrutivo - desse processo. Embora a autora não explore essa perspectiva de análise, é possível sustentar que a sexualidade feminina não foi simplesmente normalizada por meio de práticas discursivas e tornada objeto de saberes; ela foi reprimida e transformada em trabalho não remunerado no interior de uma realidade social em que o dinheiro confere poder e status. O nascimento da mulher moderna por meio da usurpação de sua sexualidade e de seus saberes historicamente constituídos é, portanto, um ponto cego do processo de acumulação primitiva do capital e, ainda, do processo de instituição das modernas relações de poder. Esse nascimento seria incompreensível sem a análise da repressão estatal às mulheres configurada pelo amplo processo de caça às bruxas, isto é, sem que se dê a devida atenção ao papel decisivo do dispositivo de soberania nesse contexto.

A disciplina, segundo Foucault, não visa a transformação dos indivíduos por meio da intervenção sobre suas representações - ou por meio de uma ideologia; ela age no corpo, a assim reforma seus hábitos, transforma a alma, e dá nascimento ao indivíduo. Por isso, segundo Foucault, o poder disciplinar é antes produtivo que repressivo: ele não depende do engendramento de falsas representações, pois incide diretamente sobre o amplo espectro dos comportamentos e das práticas (cf. Deleuze, 2005). Ora, o que o espetáculo de caça às bruxas ancorado em ações estatais repressivas e violentas - pode nos ensinar sobre o adestramento das mulheres, para além do que Foucault foi capaz de nos apresentar por meio de sua genealogia do dispositivo de sexualidade? Esse espetáculo nos ensina que a história da sexualidade se desenrolou de maneira diversa para homens e mulheres, e que estas ainda estão sob o jugo da lei e da soberania. Ademais, uma vez que, segundo Federici, o adestramento e a normalização das mulheres se dá por meio da tortura e da repressão, e não apenas pela administração dos comportamentos, é possível projetar essa discussão para o estudo do funcionamento atual do capitalismo de modo a dar conta da misoginia aí presente. Eis que chegamos a mais uma conclusão fundamental, extraída por Federici: 
Assim como atualmente, ao reprimir as mulheres, as classes dominantes reprimiam de forma ainda mais eficaz o proletariado como um todo. Instigavam os homens que foram expropriados, empobrecidos e criminalizados a culpar a bruxa castradora por sua desgraça e a enxergar o poder que as mulheres tinham ganhado contra as autoridades como um poder que as mulheres utilizariam contra eles. Todos os medos profundamente arraigados que os homens nutriam em relação às mulheres (principalmente devido à propaganda misógina da Igreja) foram mobilizados nesse contexto. As mulheres não só foram acusadas de tornar os homens impotentes, mas também sua sexualidade foi transformada num objeto de temor, uma força perigosa, demoníaca, pois se ensinava aos homens que uma bruxa podia escraviza-los e acorrenta-los segundo a sua vontade (Federici, 2017, p. 341).

Assim como outros autores, Federici sustenta a ideia de que a acumulação primitiva não é um evento restrito à pré-história do capitalismo, pois ela acompanha os processos de exploração de mais-valor inerente ao sistema. Mais que isso, nos momentos históricos em que o capitalismo passa por crises - tais como a que vivemos atualmente, no contexto neoliberal - novos mecanismos de acumulação primitiva são postos em marcha, e, mais uma vez, eles atingem as mulheres preferencialmente. ${ }^{73}$ A regulação do sistema, depende, portanto, da constante repressão das mulheres, e de sua ampla exploração e subordinação aos homens e ao Estado. Desse modo, essa gênese feminista do capitalismo, a qual reconfigura a compreensão dos processos de acumulação primitiva e de exploração de mais-valor, mostra-se, portanto, pertinente para o estudo neoliberalismo e de sua misoginia endógena. Mais que isso, ela mostra o laço profundo que une a luta das mulheres de hoje à resistência das bruxas de outrora.

\footnotetext{
73 Luxemburgo e, mais recentemente, Harvey defendem também a coexistência entre exploração e acumulação por meios violentos (saque, expropriação, etc.), contrariando, assim, a tese de Marx, a qual situa a acumulação primitiva apenas na pré-história do capitalismo. A respeito, cf. Harvey, 2013, p. 292.
} 


\section{Referências:}

Davis, Angela. Mulheres, Raça e Classe. Trad. de Heci Regina Candiani. São Paulo: Boitempo, 2016.

Deleuze, Gilles. Foucault. Trad. de Claudia Sant'Anna Martins. São Paulo : Brasiliende, 2005.

Federici, Silvia. Calibã e a Bruxa - Mulheres, Corpo e Acumulação Primitiva. Trad. Coletivo Sycorax. São Paulo: Elefante, 2017.

Foucault, Michel. Histoire de la sexualité I - La volonté de savoir. Paris : Gallimard, 1976. Gallimard, 1975. Surveiller et punir - Naissance de la prison. Paris:

Harvey, David. Para Entender o Capital, Livro I. Trad. de Rubens Enderle. São Paulo: Biotempo, 2013.

Marx, Karl. O Capital. Livro I. Trad. de Rubens Enderle. São Paulo: Boitempo, 2013. 